\title{
Numerical Simulation of Dynamic Characteristics of Dam Concrete Based on Fuzzy Set
}

\author{
Fang Jianyin (iD, Liu Ke, Dang Faning, and Li Shutian \\ Institute of Geotechnical Engineering, Xi'an University of Technology, Xi'an 710048, China \\ Correspondence should be addressed to Fang Jianyin; fjylxr@163.com
}

Received 11 April 2021; Accepted 16 September 2021; Published 4 October 2021

Academic Editor: Jinze Xu

Copyright (C) 2021 Fang Jianyin et al. This is an open access article distributed under the Creative Commons Attribution License, which permits unrestricted use, distribution, and reproduction in any medium, provided the original work is properly cited.

\begin{abstract}
The dynamic characteristics of concrete are the key point of the dam seismic safety design. In order to study the dynamic characteristics of concrete, a CT scan test of concrete under dynamic load was carried out; CT scan images of the concrete loading process were obtained. Based on the definition of integrity, integrity area, and intercepted sections in the quantitative zoning theory, the concrete CT images were divided into the hole or crack area $\left(P_{0-\lambda_{1}}\right)$, hardened cement stone area $\left(P_{\lambda_{1}-\lambda_{2}}\right)$, and aggregate area $\left(P_{\lambda_{2}-1}\right)$. And the determination method of partition threshold is studied. Then, based on the CT resolution unit, a concrete numerical calculation model of structural random is established, and the numerical simulation experiment of concrete under uniaxial dynamic load is carried out. The results show that the concrete numerical calculation model of structural random is very close to the actual mesostructure of concrete, and the interface thickness between aggregate and hardened cement is very close to the actual interface thickness (which is $40 \sim 50 \mu \mathrm{m}$ ). Under the action of dynamic load, the damage of the sample is mainly concentrated in the upper part of the sample, and the damage is easy to occur at the initial defect place, and the damage occurs at multiple points at the same time. The damage crack is relatively straight, the phenomenon of the crack passing through the aggregate is obvious, and the crack expands along the fastest path of energy release.
\end{abstract}

\section{Instruction}

The mechanical properties of concrete are related to the safety evaluation of the dam concrete structure under dynamic load, which is the focus of current research. Since the concept of numerical concrete appeared, the mesoscale numerical model based on the finite element has been widely used in the study of dynamic characteristics of concrete.

Yong et al. [1] established a three-dimensional random aggregate model and carried out numerical simulation research on concrete target penetration tests by using LSDYNA software. Chen et al. [2] developed a mesomechanical pretreatment algorithm to construct the random ellipsoidal aggregate model for the mesoscopic structure of fully graded concrete. Yuan et al. [3] studied the dynamic strength characteristics of dam concrete using the random aggregate model. Yue et al. [4] simulated the dynamic tensile properties of coral aggregate seawater con- crete by using the 3D mesoscopic concrete model. In these models and methods, concrete is considered to be composed of aggregate, mortar, and interface [5-6]. The mortar matrix, aggregate, pore, and interface have significant influence on the mechanical properties of concrete [7-8]. Therefore, in the process of simulating the mechanical behavior and damage characteristics of concrete, it is very important to represent the mesostructure of concrete as realistically as possible in the numerical model. A large number of researchers [9-16] have reconstructed twodimensional or three-dimensional concrete numerical calculation models based on X-ray CT scanning technology, and the mechanical properties of concrete are studied by using the model. Ju et al. [17] propose using a l CT technique to acquire the real structural information of SRM samples and constructing a 3D SRM model in PFC3D to represent SRM's real heterogeneity and irregular structure. Zheng et al. $[18,19]$ present a computer procedure for reconstructing the $3 \mathrm{D}$ porous structure of low- 
permeability sandstone based on the information of a reference model which is established from computed tomography (CT) images. To examine the development law of a coal fracture structure under uniaxial compression, tension, and shearing, Hao et al. [20] have scanned the coal after loading using computed tomography (CT) and segmented the coal matrix, minerals, and fractures in the CT scanning image of the coal by using a threshold segmentation method. Wang et al. [21, 22] have established the three-dimensional numerical model of a coal sample based on a CT scanning image and studied the seepage and deformation characteristics of different pore-fracture structures of coal at different temperatures.

However, the elements of these models have great singularity, and the thickness of the interface in the model is large, which still has a certain gap with the real concrete.

To this end, the CT test of concrete under dynamic uniaxial compression was carried out, and the concrete scanning images were quantitatively divided based on the damage zoning theory, and a structural random type numerical concrete model was established; the mechanical properties of concrete under uniaxial dynamic compression stress were studied by using the model.

1.1. Uniaxial Dynamic Compression CT Test. This test adopts the newly developed portable power loading equipment of Xi'an University of Technology, which is the first power loading test equipment with CT scanners in China [23]. The CT scanner uses a Marconi M8000 spiral CT scanner with an image size of $1024 \times 1024$. The maximum imaging speed is 0.5 seconds for four-layer scanning. The loading scanning device is shown in Figure 1.

This test uses a first-grade C15 concrete cylinder test piece, the diameter of the samples is $60 \mathrm{~mm}$, and the length is $120 \mathrm{~mm}$; the water-cement ratio is 0.4 , and the aggregate particle size is $5-20 \mathrm{~mm}$. Samples are cured for 28 days under standard conditions, and the test is then conducted.

In the test, the frequency of sinusoidal wave load was $2 \mathrm{~Hz}$, and each amplitude had more than 3 vibration times, gradually increasing the amplitude. In the initial stage of uniaxial compression, stress control loading is adopted. After the second scan, the loading was changed to displacement control, and the load increment is $0.002 \mathrm{~mm}$. During the scanning, the loading was stopped, but the unloading was not carried out, and the pressure peak was maintained. A total of 7 scans were carried out until the test was stopped when the sample was damaged. The scanning position is shown in Figure 2, and the CT images of sample damage are shown in Figure 3.

\section{The Establishment of "Structural Random Type Numerical Concrete Model"}

\subsection{Quantitative Partitioning Theory}

2.1.1. Integrity Degree. On the basis of fuzzy mathematics theory, the entire CT scan image is called the whole field, which is represented by a set as $\Omega=\{(x, y, z) \mid(x, y, z)$ is an

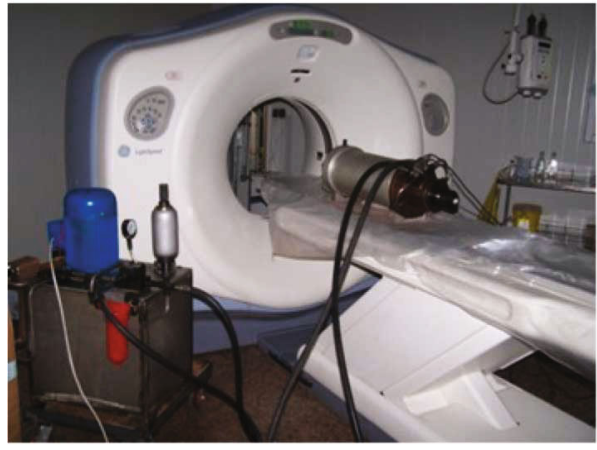

Figure 1: Portable dynamic loading equipment and CT scanner (reproduced from Fang et al. [24]).

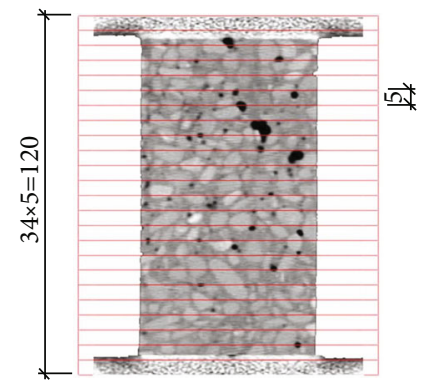

FIgURE 2: CT scan localization of the sample (reproduced from Fang et al. [24]).

arbitrary point on the study object space area $\}$. Any point in the whole field is complete, but the integrity is different. On this basis, the integrity can be defined as follows:

$$
P(x, y, z)=\frac{H(x, y, z)+1000}{\max H(x, y, z)+1000},
$$

where $H(x, y, z)$ is the CT number of the space point $(x, y, z)$ , which can be defined as follows:

$$
H(x, y, z)=\frac{\mu t-\mu_{w}}{\mu_{w}} \times 1000
$$

where $\mu_{t}$ and $\mu_{w}$ are the $\mathrm{X}$-ray linear attenuation coefficients of minerals and water in the scanned image, respectively.

According to this definition, the integrity degree is in the interval of $[0,1]$.

With the increase of the load, the scanning images of each section are unique, and the CT number distribution of each section is different. The normalized CT number, integrity, and breakage have universal applicability, which greatly simplifies the research of concrete CT tests.

2.1.2. Horizontal Integrity Domain of $\lambda$. The integrity of the study area and the phenomenon of fracture were blurred by the concept of integrity degree. In order to study the crack evolution law of concrete with a clear physical concept and connect the macrofracture with the microdamage, the concept of integrity level is introduced here. 


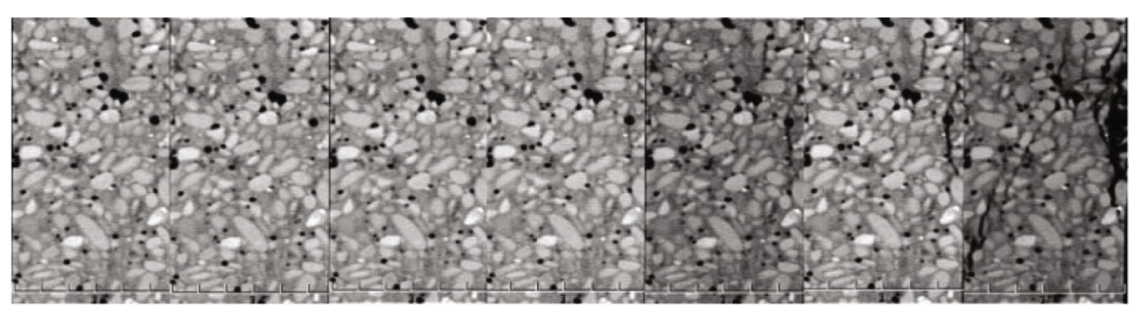

Figure 3: CT images of samples.

Assuming that $0 \leq \lambda \leq 1$, set

$$
\{(x, y, z) \mid 1 \leq P(x, y, x) \leq \lambda,(x, y, z) \in \Omega\}
$$

is defined as the $\lambda$ level complete domain of the sample, expressed by $P_{\lambda}$.

The integrity domain $P_{\lambda}$ is essentially the set of all CT resolution units whose CT number is greater than a certain threshold value. It can be seen that, as long as the value of $\lambda$ is properly selected, $P_{\lambda}$ represents the collection of all CT points whose density is less than a certain threshold, which is the crack area or the damage area.

Therefore, the $\lambda$ horizontal integrity domain of the sample can be regarded as the damage region of classical damage mechanics or the crack of fracture mechanics, thus realizing the transition from microscopic to macroscopic and linking the damage and fracture of concrete.

2.1.3. $\left(\lambda_{1}-\lambda_{2}\right)$ Intercepted Section. The study of $\lambda$ horizontal integrity domain is only a resolution unit from 1 to $\lambda$. However, concrete is a multiphase material composed of aggregate, hardened cement, and cavity cracks. In order to distinguish them, the definition of $\left(\lambda_{1}-\lambda_{2}\right)$ intercepted section can be introduced to describe it.

Assuming that $0 \leq \lambda_{1} \leq \lambda_{2} \leq 1$, set

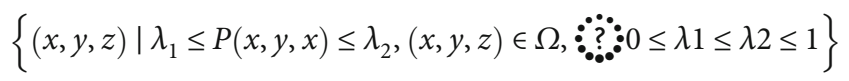

is defined as $\left(\lambda_{1}-\lambda_{2}\right)$ complete domain intercepted sections, expressed by $P_{\lambda_{1}-\lambda_{2}}$. In fact, the intercepted section is a statistical resolution unit in which the density of the sample is close within the interval $\lambda_{1}-\lambda_{2}$. The connotation of the intercepted section is very simple, but its extension is very rich. In practice, the intercepted section can be applied to delamination of foundation, definition of joint interlayer, division of fracture zone, division of rock or concrete, definition of material integrity, damage and fracture zone, etc.

Figure 4 shows the partition intercepted sections of a scan section of a concrete sample. The intercepted sections can distinguish well the materials of different densities in the concrete, such as aggregates, cement mortar, and cracks.

2.2. Quantitative Partitioning. The specific definition is as follows:
When $0 \leq P(x, y, x)<\lambda_{1}$, the material is believed to contain pores or is fractured. It is called the hole crack area and is denoted as $P_{0-\lambda_{1}}$.

When $\lambda_{1} \leq P(x, y, x)<\lambda_{2}$, the material integrity is considered general, and the material is in the hardened cement zone $t$ and is denoted as $P_{\lambda_{1}-\lambda_{2}}$.

When $\lambda_{2} \leq P(x, y, x) \leq 1$, the material integrity is high in the aggregate area (coarse and fine aggregates) and is denoted as $P_{\lambda_{2}-1}$.

$\lambda_{1}$ is the threshold of the crack zone and the hardened cement zone, and $\lambda_{2}$ is the threshold of the hardened cement and aggregate areas. $\lambda_{1}$ and $\lambda_{2}$ are the material parameters, which are constant.

The focus of the partition is how to determine reasonable partition thresholds $\lambda_{1}$ and $\lambda_{2}$. For homogeneous rocks, $\lambda_{1}$ and $\lambda_{2}$ can be obtained using the maximumminimum method. However, for concrete, this method cannot be used. This method is proposed based on homogeneous materials. Hence, its applicability to heterogeneous materials, such as concrete, is limited. Therefore, the method of probability statistics is used to determine the threshold.

Concrete is a composite material composed of aggregates, mortar, and ITZ. The idea of partition indicates that a component of its resolution unit should be continuous and gradually distributed to avoid large jump changes. The distribution of the resolution units among different components is bound to a certain jump. This idea indicates that to select a CT scan as a universe $\Omega$, a total of 137027 resolution units are required. The statistical relationship between the threshold and the resolution unit is shown in Figure 5, where the abscissa is the threshold, and the ordinate is the corresponding number of statistical units.

As shown in Figure 5, when the thresholds are approximately 0.7 and 0.84 , the number of statistical resolution units has a large jump; therefore, $\lambda_{1}$ and $\lambda_{2}$ are 0.7 and 0.84 , respectively.

2.3. Modeling Ideas. First of all, CT scan images need to be processed, which includes image positioning and image CT number extraction. The source program is written in FORTRAN language to read the CT scan data files, and the detailed location is carried out according to the image. The positioning accuracy is one CT resolution point (about $0.009 \mathrm{~mm}$ ), based on which the reconstruction range of the model was determined, and then, the 


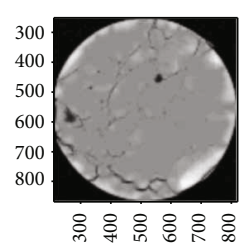

(a) $\lambda=0-0.6$

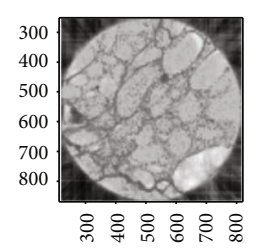

(b) $\lambda=0.6-0.7$

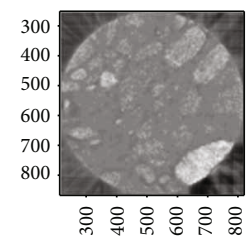

(c) $\lambda=0.7-1$

FIGURE 4: Intercepted sections of complete domain.

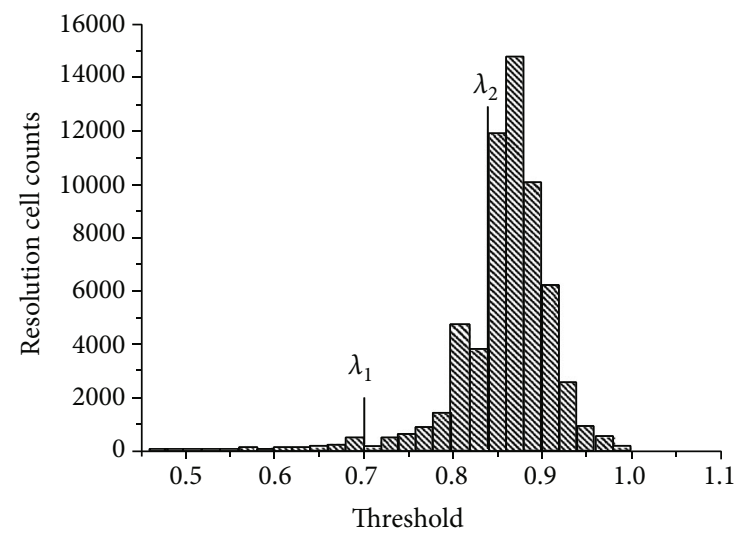

FIGURE 5: Relationship of threshold and resolution cell (reproduced from Fang et al. [24]).

CT number within the reconstruction range was extracted.

In the CT image, the larger the CT number, the higher the brightness, which represents the greater the density of the material. In the image, the brighter place is aggregate (coarse aggregate and fine aggregate), the gray area is mortar (the product of cement hydration and hardening), and the black area is the hole and crack.

Using the quantitative zoning theory, the FORTRAN source program was compiled to process the extracted CT numbers, and then, the "concrete numerical model of structure random" was reconstructed on the finite element software. The specific modeling ideas are shown in Figure 6.

The "concrete numerical model of structure random" established according to the above modeling ideas is shown in Figure 7.

\section{Numerical Experimental Study Based on Structural Randomness}

3.1. Numerical Test Conditions. In accordance with the physical tests, the material parameters as shown in Table 1 can be obtained.
In the numerical simulation, the constraint conditions are the full constraint of the sample bottom surface and the horizontal constraint of the sample top surface. The failure of concrete under load is caused by material damage. The elastoplastic damage model can be used as a theoretical tool to deal with the stress damage of concrete materials. Therefore, this paper uses the plastic damage model, which is based on plasticity and assumes that concrete material has two kinds of damage, one is the tensile damage $d_{t}$ caused by the principal tensile stress, and the other is the pressure damage $d_{c}$ caused by crushing under pressure. For damage variables $d_{t}$ and $d_{c}$, their value range is $[0,1]$. When 0 , it means that the material is complete without damage, and when 1 , it means that the material is completely damaged.

The model is described by effective stress and hardening variables:

$$
\begin{gathered}
\bar{\sigma}=D_{0}^{\mathrm{el}}:\left(\varepsilon-\varepsilon^{\mathrm{pl}}\right) \in\left\{\bar{\sigma} \mid F\left(\bar{\sigma}, \tilde{\varepsilon}^{\mathrm{pl}}\right) \leq 0\right\} \\
\dot{\tilde{\sigma}}^{\mathrm{pl}}=h\left(\bar{\sigma}, \tilde{\mathcal{\varepsilon}}^{\mathrm{pi}}\right) * \dot{\varepsilon}^{\mathrm{pl}} \\
\dot{\mathcal{\varepsilon}}^{\mathrm{pl}}=\dot{\lambda} \frac{\partial G(\bar{\sigma})}{\partial \bar{\sigma}}
\end{gathered}
$$

$\dot{\lambda}$ and $F$ should satisfy the Kuhn-Tucker condition, namely, $\dot{\lambda} F \leq 0, \dot{\lambda} \geq 0, F \leq 0$.

Cauchy stress can be obtained by using damage factor $d\left(\bar{\sigma}, \tilde{\varepsilon}^{\mathrm{pl}}\right)$ and effective stress:

$$
\sigma=(1-d) \bar{\sigma}
$$

The damage deformation of the material under uniaxial tensile load is shown in Figure 8. $\sigma_{c 0}$ is the stress at failure. When the stress is before the initial yield stress $\sigma_{c 0}$, the relationship between tensile stress and strain is linear (linear elastic relationship), and then, the material enters the softening deformation stage. In this process, the stiffness of the material degenerates. When the material cracks, the strain 


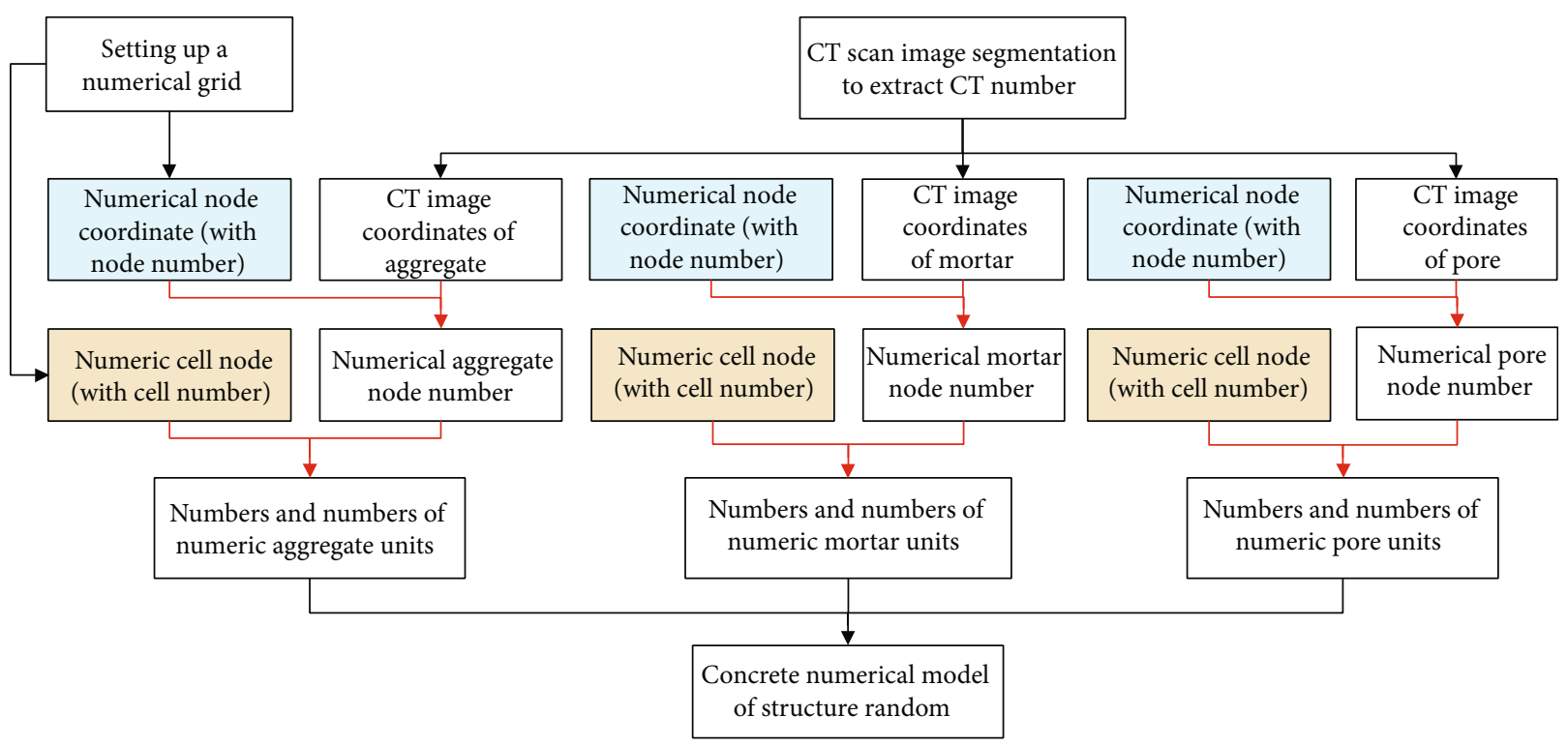

FIgURE 6: Model ideas of concrete numerical model of structure random.

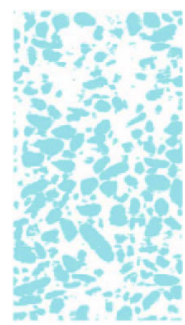

(a) Aggregate

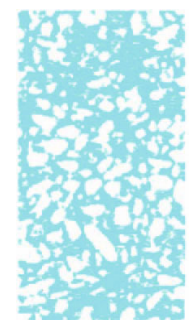

(b) Cement mortar

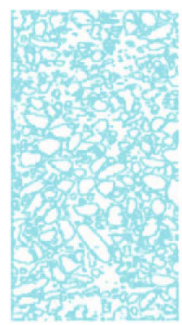

(c) ITZ

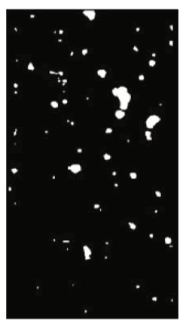

(d) Hole

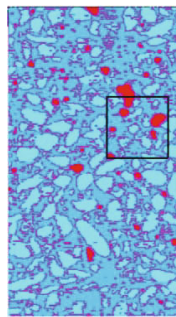

(e) The overall model

Figure 7: Concrete numerical model of structure random.

TABLE 1: Material parameter of concrete components (reproduced from Fang et al. [24]).

\begin{tabular}{lcccc}
\hline Material & $\begin{array}{c}\text { Elastic } \\
\text { modulus } \\
(\mathrm{GPa})\end{array}$ & $\begin{array}{c}\text { Poisson's } \\
\text { ratio }\end{array}$ & $\begin{array}{c}\text { Tensile } \\
\text { strength } \\
(\mathrm{MPa})\end{array}$ & $\begin{array}{c}\text { Density } \\
\left(\mathrm{kg} / \mathrm{m}^{3}\right)\end{array}$ \\
\hline Aggregate & 58.731 & 0.2407 & 9.25 & 2800 \\
Motor & 17.458 & 0.1960 & 2.78 & 2200 \\
ITZ & 13.967 & 0.2000 & 1.56 & 2000 \\
\hline
\end{tabular}

can be expressed as

$$
\begin{gathered}
\tilde{\varepsilon}_{t}^{\mathrm{ck}}=\varepsilon_{t}-\varepsilon_{0 t}^{\mathrm{el}}, \\
\varepsilon_{0 t}^{\mathrm{el}}=\frac{\sigma_{t}}{E_{0}} .
\end{gathered}
$$

It can be obtained from Figure 8:

$$
\tilde{\varepsilon}_{t}^{\mathrm{pl}}=\tilde{\varepsilon}_{t}^{\mathrm{ck}}-\frac{d_{t}}{\left(1-d_{t}\right)} \frac{\sigma_{t}}{E_{0}} .
$$

Under the action of uniaxial compression load, when the stress is before the initial yield stress $\left(\sigma_{c 0}\right)$, the stress-strain

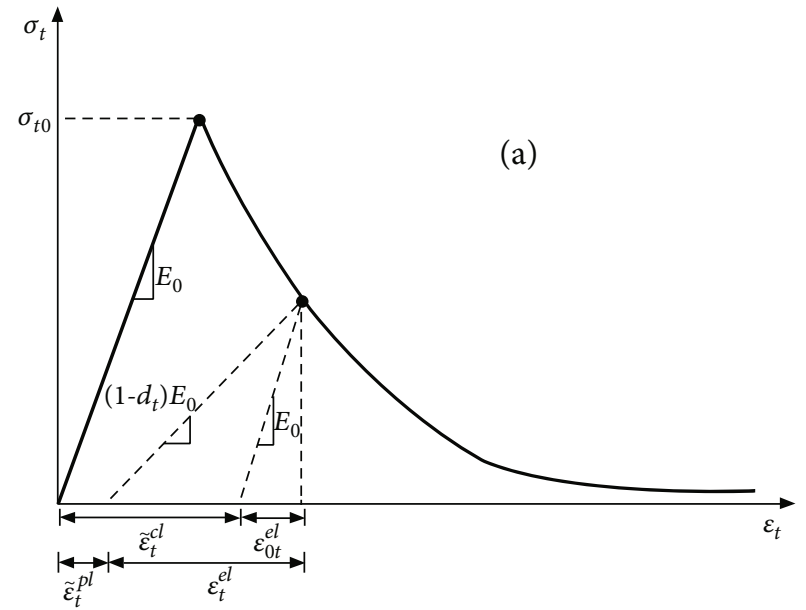

FIgURE 8: Tensile stress and strain.

relationship of the material is linear elastic, and this stage is the elastic deformation stage. When the stress is between $\sigma_{c 0}$ and the ultimate stress $\left(\sigma_{c u}\right)$, the material is in the strengthening stage, and then, the strain continues to increase and the material enters the softening stage.

According to $\tilde{\varepsilon}_{c}^{\text {in }}$ (inelastic strain), the corresponding hardening data can be obtained. 


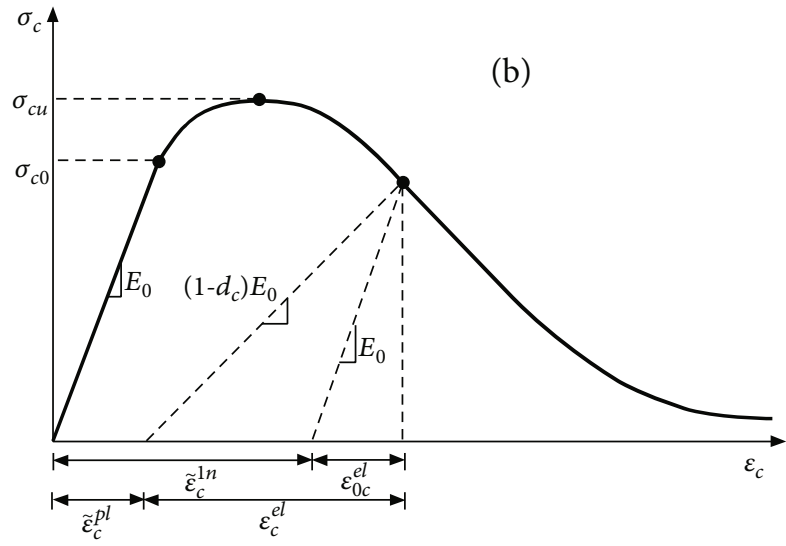

Figure 9: Compression stress and strain.

As can be seen from Figure 9, $\tilde{\varepsilon}_{c}^{\text {in }}$ has the following relationship with $\varepsilon_{0 c}^{\mathrm{el}}$ :

$$
\begin{gathered}
\tilde{\varepsilon}_{c}^{\text {in }}=\varepsilon_{c}-\varepsilon_{0 c}^{\mathrm{el}}, \\
\varepsilon_{0 c}^{\mathrm{el}}=\frac{\sigma_{c}}{E_{0}} .
\end{gathered}
$$

Therefore, it can be obtained from Figure 9.

$$
\tilde{\varepsilon}_{c}^{\mathrm{pl}}=\tilde{\varepsilon}_{c}^{\mathrm{in}}-\frac{d_{c}}{\left(1-d_{c}\right)} \frac{\sigma_{c}}{E_{0}} .
$$

Then, the stress-strain relationship under tension and compression can be obtained:

$$
\begin{gathered}
\sigma_{t}=\left(1-d_{t}\right) E_{0}\left(\varepsilon_{t}-\tilde{\varepsilon}_{t}^{\mathrm{pl}}\right), \\
\sigma_{c}=\left(1-d_{c}\right) E_{0}\left(\varepsilon_{c}-\tilde{\varepsilon}_{c}^{\mathrm{pl}}\right) .
\end{gathered}
$$

The model assumes that the stiffness degradation is isotropic and can be described by a scalar parameter $D$ :

$$
\begin{aligned}
E & =(1-d) E_{0}(0 \leq d \leq 1), \\
(1-d) & =\left(1-s_{t} d_{c}\right)-\left(0 \leq s_{t}, s_{c} \leq 1\right) .
\end{aligned}
$$

$s_{t}$ and $s_{c}$ are related to the stress state of the material and can be expressed as

$$
\begin{gathered}
s_{t}=1-w_{t} r^{*}\left(\bar{\sigma}_{11}\right)-0 \leq w_{t} \leq 1, \\
s_{c}=1-w_{c}\left[1-r^{*}\left(\bar{\sigma}_{11}\right)\right]-0 \leq w_{c} \leq 1, \\
r^{*}\left(\bar{\sigma}_{11}\right)=H\left(\bar{\sigma}_{11}\right)=\left\{\begin{array}{l}
1\left(\bar{\sigma}_{11}>0\right), \\
0\left(\bar{\sigma}_{11}<0\right),
\end{array}\right.
\end{gathered}
$$

where $w_{t}$ and $w_{c}$ are weight factors. According to Figure 10, when $\varepsilon_{c}^{\mathrm{pl}}=0, d_{c}=0$, then

$$
(1-d)=\left(1-s_{c} d_{t}\right)=1-\left(1-w_{c}\left(1-r^{*}\right) d_{t}\right) .
$$

In equation (15), when the material is in the state of tensile stress, $r *(\bar{\sigma})=H(\bar{\sigma})=1$ and $d=d_{t}$. When the material is in the state of compressive stress, $d=\left(1-w_{c}\right) d_{t}$. If $w_{c}=1$, then $d=0$, the compression stiffness has been restored at this time. If $w_{c}=0$ and $d=d_{t}$, the stiffness is not restored. If $0 \leq w_{c} \leq 1$, the stiffness is partially restored.

Due to the great difference between the tensile and compressive properties of concrete, the damage factor $D$ can be calculated according to the tensile and compressive conditions, respectively. The compressive damage factor can be obtained from equation (12):

$$
d_{c}=\frac{1-\sigma_{c} E_{0}^{-1}}{\varepsilon_{c}-\tilde{\varepsilon}_{c}^{\mathrm{pl}}} .
$$

By substituting $\varepsilon_{c}=\varepsilon_{c}^{\mathrm{in}}+\varepsilon_{0 c}^{\mathrm{el}}$ and $\varepsilon_{0 c}^{\mathrm{el}}=\sigma_{c} E_{0}^{-1}$ into equation (12), we can get

$$
d_{c}=1-\frac{\sigma_{c} E_{0}^{-1}}{\tilde{\tilde{\varepsilon}}_{c}^{\mathrm{pl}}\left(1 / b_{c}-1\right)+\sigma_{c} E_{0}^{-1}},
$$

where $b_{c}=\tilde{\varepsilon}_{c}^{\mathrm{p}} / \varepsilon_{c}^{\mathrm{in}}$.

Similarly, the cordera damage factor:

$$
d_{t}=1-\frac{\sigma_{t} E_{0}^{-1}}{\tilde{\varepsilon}_{t}^{\mathrm{pl}}\left(1 / b_{t}-1\right)+\sigma_{t} E_{0}^{-1}},
$$

where $b_{t}=\tilde{\varepsilon}_{t}^{\mathrm{pl}} / \varepsilon_{t}^{\mathrm{ck}}$.

3.2. Analysis of Test Results. According to the above calculation conditions, the concrete numerical simulation test is carried out, and the nephogram of displacement and damage of the specimen under dynamic load with the change of load can be obtained, as shown in Figures 11 and 12 .

It can be seen from Figure 11 that the longitudinal displacement of the concrete sample changes more evenly at the initial stage of loading. The displacement at the top of the sample is larger than that at the bottom, and there is a sudden change in the displacement near the initial defects (holes and cracks). This is due to the stress concentration near the initial defect, which leads to the strain localization of the specimen, which is consistent with the understanding of the compression densification of the specimen. With the further increase of displacement loading, new damage cracks appear in the specimen, and the displacement of the initial defect in the specimen mutates further, resulting in more uneven displacement in the whole section of the specimen. It can be found from Figure 11 that the more concentrated the initial defects are, the easier the specimen will be damaged, the more obvious the stress concentration is, and the more obvious the displacement mutation is. This explains the origin of strain localization from one side.

It can be seen from Figure 12 that under the dynamic load, the damage in the sample is mainly concentrated in the upper part of the sample, and it is easy to cause damage in the initial defects of the sample, and multipoint damage occurs at the same time. The damage crack is relatively 


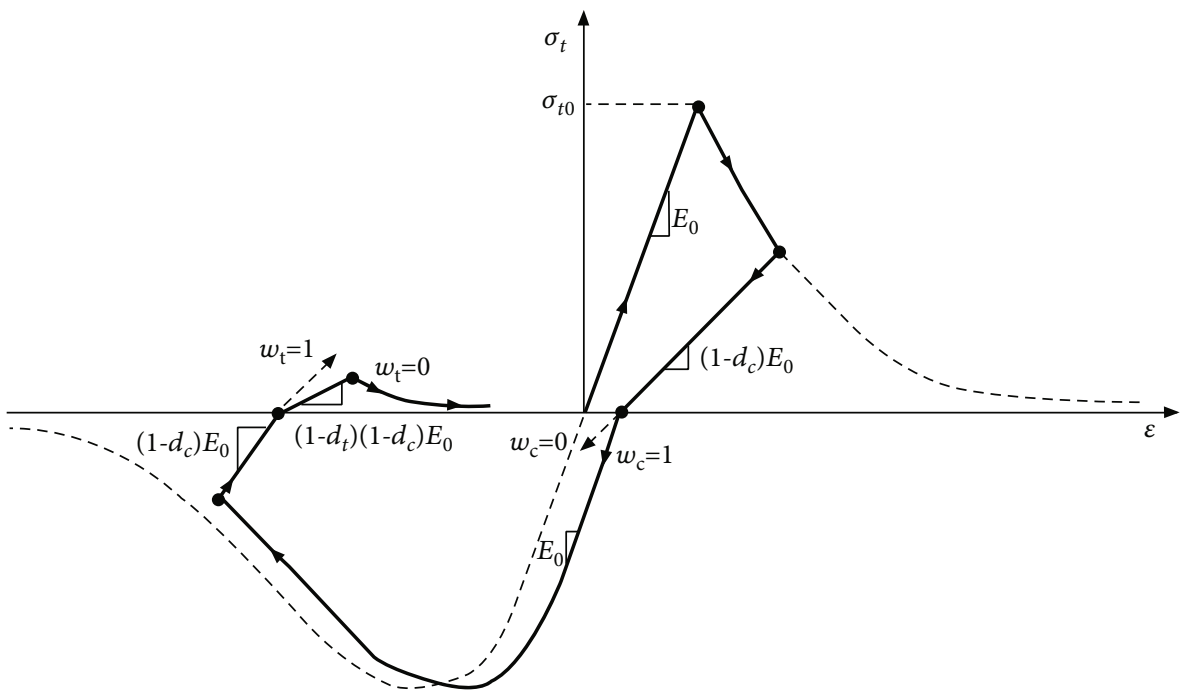

FIgURE 10: Stress cycling curve of concrete under uniaxial loading.
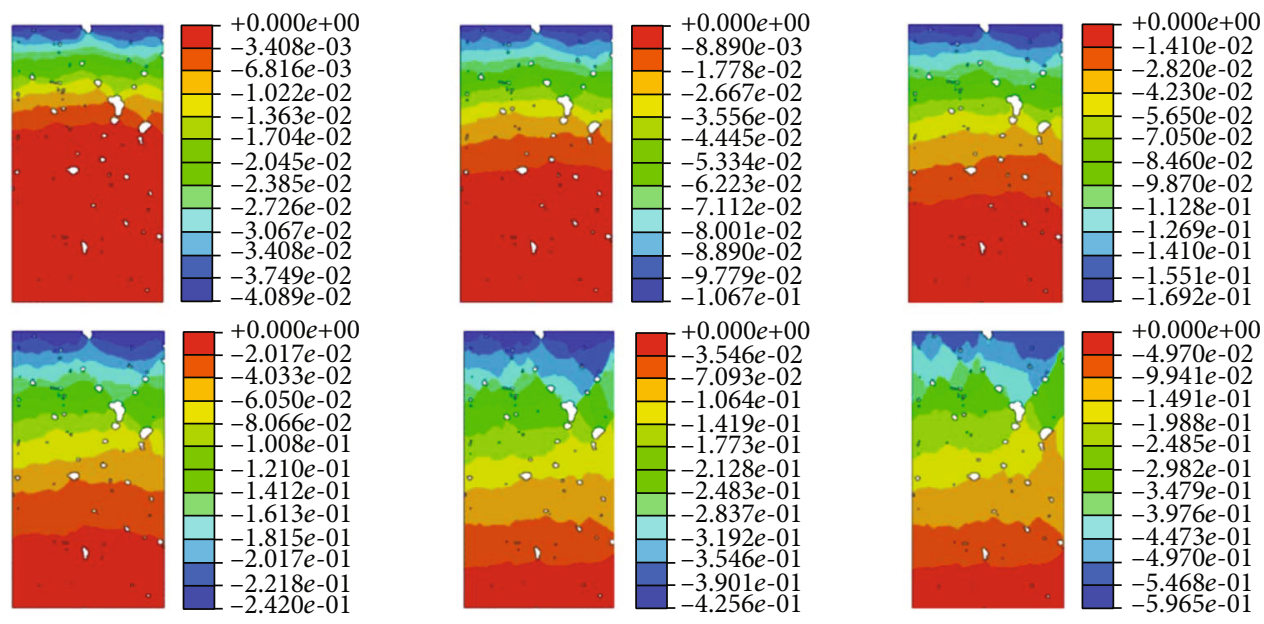

FIGURE 11: Longitudinal displacement of concrete under dynamic loading.
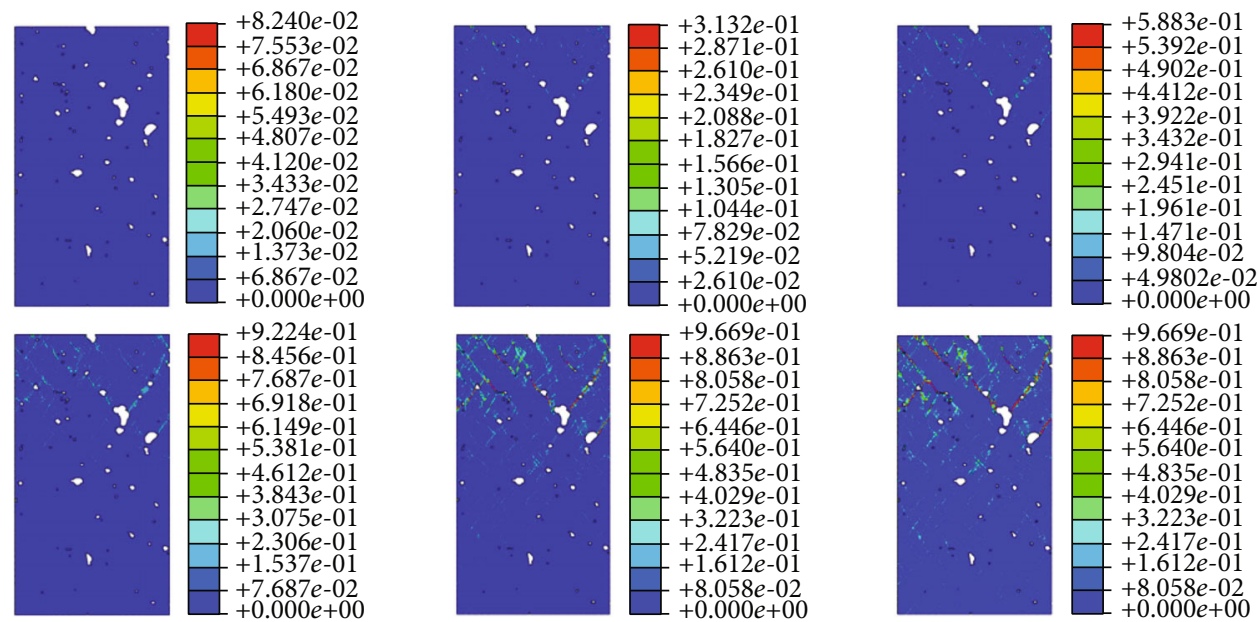

$+9.669 e-01$

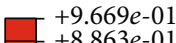

$+\begin{array}{r}+8.863 e-01 \\ +8.058 e-01\end{array}$

$+7.252 e-01$

$+5.640 e-01$

$+4.835 e-01$

$++4.029 e-01$

$\begin{array}{r}+4.029 e-01 \\ + \\ +\end{array}+2.417 e-01$

$++1.612 e-01$

$+8.058 e-02$

Figure 12: Damage evolution of concrete. 
straight, and the phenomenon around the aggregate is not obvious. In some places, there is a phenomenon that the crack passes through the aggregate. This is different from the development of cracks around the interface with weak aggregate strength under static load.

The main reason is that under the action of dynamic load, due to the fast loading rate, the crack develops rapidly, so the crack has no time to follow the weak surface around the aggregate but follows the path of rapid energy release. This is consistent with the results of the physical CT test of coagulation under dynamic action.

Through the above analysis, it is found that the dynamic numerical simulation test by using the "structural random concrete numerical model" shows that the displacement and damage change law of concrete is very similar to the conclusion of the current physical test institute, which indicates that the model established in this paper is more practi$\mathrm{cal}$ in simulating the dynamic test of concrete.

\section{Conclusions}

In this paper, the CT test of concrete under dynamic uniaxial compression was carried out, the "structure random concrete numerical model" was constructed based on the CT images, and the mechanical properties of concrete under uniaxial dynamic compression stress were studied by using the model. The conclusions of this study are as follows.

(1) Based on the concrete CT test of dynamic loading and quantitative partition theory, the probabilistic statistical method to determine the subdivision threshold is proposed, and the "structure random concrete numerical model" was established based on CT resolution units. The "concrete numerical model of structure random" is very close to the real mesostructure of concrete; it can describe the mesostructure of concrete and can reflect the aggregate and the hardening cement interface. Moreover, the thickness of the interface is about $0.04 \mathrm{~mm}$, which is very close to the real interface thickness (about 10-50 $\mu \mathrm{m}$ )

(2) Under the action of dynamic load, the damage in the sample is mainly concentrated in the upper part of the sample, and it is easy to cause damage in the initial defects of the sample, and multipoint damage occurs at the same time. The damage crack of concrete develops rapidly; the crack does not have enough time to follow the weak side around the aggregates but follows the path of energy release fast

\section{Data Availability}

The basic data supporting my research results can be found in the article.

\section{Conflicts of Interest}

The authors declare that they have no conflicts of interest.

\section{Acknowledgments}

The research is funded by the Natural Science Foundation of China (No. 51979225), Natural Science Foundation of Shaanxi Provincial Department of Education of China (No. 18JK0547), Science and technology innovation project of Xi'an University of Technology (No. 2016CX026), and Xi'an University of Technology School Doctor Gold (No. 107451116012).

\section{References}

[1] Y. Yong, Y. Deng, and C. Daiguo, "Numerical modeling study on the penetration impact of concrete mesoscopic composition," Chinese Journal of Applied Mechanics, vol. 1, pp. 6975, 2015.

[2] C. Chen, S. Bai, Y. Huang, L. Lam, Y. Yao, and L. M. Keer, “3D random packing algorithm of ellipsoidal particles based on the Monte Carlo method," Magazine of Concrete Research, vol. 73, no. 7, pp. 343-355, 2021.

[3] Q. I. N. Yuan, C. H. A. I. Jun-rui, and D. A. N. G. Fa-ning, "Numerical analysis on static and dynamic strength of dam concrete," Journal of Water Resources and Architectural Engineering, vol. 11, no. 1, pp. 1-6, 2013.

[4] C. J. Yue, H. Y. Ma, H. F. Yu et al., "Experimental and threedimensional mesoscopic simulation study on coral aggregate seawater concrete with dynamic direct tensile technology," International Journal of Impact Engineering, vol. 150, p. 103776, 2021.

[5] W. Ren, Z. Yang, R. Sharma, C. Zhang, and P. J. Withers, "Two-dimensional X-ray CT image based meso-scale fracture modelling of concrete," Engineering Fracture Mechanics, vol. 133, pp. 24-39, 2015.

[6] H. S. Wong, M. Zobel, N. R. Buenfeld, and R. W. Zimmerman, "Influence of the interfacial transition zone and microcracking on the diffusivity, permeability and sorptivity of cement-based materials after drying," Magazine of Concrete Research, vol. 61, no. 8, pp. 571-589, 2009.

[7] Q. Yu, H. Liu, T. Yang, and H. Liu, "3D numerical study on fracture process of concrete with different ITZ properties using $\mathrm{X}$-ray computerized tomography," International Journal of Solids and Structures, vol. 147, pp. 204-222, 2018.

[8] H. Wang, Z. Huang, L. Li, Z. You, and C. Yu, "Three-dimensional modeling and simulation of asphalt concrete mixtures based on X-ray CT microstructure images," Journal of Traffic and Transportation Engineering (English Edition)., vol. 1, no. 1, pp. 55-61, 2014.

[9] T. I. A. N. Wei, D. A. N. G. Fa-ning, and C. H. E. N. Hou-qun, "CT experimental study on failure characteristics of concrete under dynamic loading," Journal of Earthquake Engineering And Engineering Vibration, vol. 31, no. 1, pp. 30-34, 2011.

[10] J. Kollmann, G. Lu, P. Liu et al., "Parameter optimisation of a 2D finite element model to investigate the microstructural fracture behaviour of asphalt mixtures," Theoretical and Applied Fracture Mechanics, vol. 103, p. 102319, 2019.

[11] Z. Wang, H. Li, and X. Lan, "Formation damage mechanism of a sandstone reservoir based on micro-computed tomography," Advances in Geo-Energy Research, vol. 5, no. 1, pp. 25-38, 2021.

[12] Y. Zhao, J. Jiang, Y. Dai, L. Zhou, and F. Ni, “Thermal property evaluation of porous asphalt concrete based on heterogeneous 
meso-structure finite element simulation," Applied Sciences, vol. 10 , no. 5 , p. $1671,2020$.

[13] Y. Xue, T. Teng, F. Dang, Z. Ma, S. Wang, and H. Xue, "Productivity analysis of fractured wells in reservoir of hydrogen and carbon based on dual-porosity medium model," International Journal of Hydrogen Energy, vol. 45, no. 39, pp. 20240-20249, 2020.

[14] X. Wang, H. Yin, X. Zhao, B. Li, and Y. Yang, "Microscopic remaining oil distribution and quantitative analysis of polymer flooding based on CT scanning," Advances in Geo-Energy Research, vol. 3, no. 4, pp. 448-456, 2019.

[15] H. Elaqra, N. Godin, G. Peix, M. R'Mili, and G. Fantozzi, "Damage evolution analysis in mortar, during compressive loading using acoustic emission and X-ray tomography: effects of the sand/cement ratio," Cement and Concrete Research, vol. 37, no. 5, pp. 703-713, 2007.

[16] L. Zhu, D. Faning, and D. Weihua, "Coupled X-ray computed tomography and grey level co-occurrence matrices theoryas a method for detecting microscopic damage of concrete under different loads," China Civil Engineering Journal, vol. 53, no. 8, pp. 97-107, 2020.

[17] Y. Ju, H. Sun, M. Xing, X. Wang, and J. Zheng, "Numerical analysis of the failure process of soil-rock mixtures through computed tomography and PFC3D models," International Journal of Coal Science \& Technology, vol. 5, no. 2, pp. 126$141,2018$.

[18] J. Zheng, Y. Ju, and X. Zhao, "Influence of pore structures on the mechanical behavior of low-permeability sandstones: numerical reconstruction and analysis," Int J Coal Sci Technol, vol. 1, no. 3, pp. 329-337, 2014.

[19] Y. Xue, J. Liu, P. G. Ranjith, X. Liang, and S. Wang, "Investigation of the influence of gas fracturing on fracturing characteristics of coal mass and gas extraction efficiency based on a multi-physical field model," Journal of Petroleum Science and Engineering, vol. 206, p. 109018, 2021.

[20] D. Hao, S. Tu, C. Zhang, and H. Tu, "Quantitative characterization and three-dimensional reconstruction of bituminous coal fracture development under rock mechanics testing," Fuel, vol. 267, p. 117280, 2020.

[21] G. Wang, X. Qin, D. Han, and Z. Liu, "Study on seepage and deformation characteristics of coal microstructure by $3 \mathrm{D}$ reconstruction of CT images at high temperatures," International Journal of Mining Science and Technology, vol. 31, no. 2, pp. 175-185, 2021.

[22] L. Zhu, F. Dang, Y. Xue, K. Jiao, and W. Ding, "Multivariate analysis of effects of microencapsulated phase change materials on mechanical behaviors in light-weight aggregate concrete," Journal of Building Engineering, vol. 42, p. 102783, 2021.

[23] T. I. A. N. Wei, D. A. N. G. Fa-ning, D. I. N. G. Wei-hua, L. I. A. N. G. Xin-yu, and C. H. E. N. Hou-qun, "Development of a dynamic loading apparatus for CT experiment and its application," Rock and Soil Mechanics, vol. 31, no. 1, 2010.

[24] J. Fang, Y. Pan, F. Dang, X. Zhang, J. Ren, and N. Li, “Numerical reconstruction model and simulation study of concrete based on damaged partition theory and CT number," materials, vol. 12, no. 24, p. 4070, 2019. 